\title{
The IASB Discussion Paper on Insurance: A CFO Forum Perspective*
}

\author{
Denis Duverne and Jacques Le Douit \\ AXA, Avenue Matignon 25, Paris 75008, France. \\ E-mails: denis.duverne@axa.com, jacques.ledouit@axa.com
}

The IASB has issued a Discussion Paper on accounting for insurance and reinsurance contracts. This project is based on a prospective measurement of the insurance liabilities, the current exit value, which corresponds to a "market consistent" transfer value of insurance contracts to another market participant. This project is similar to the Elaborated Principles (the EPs) proposed by the CFO Forum in June 2006: a single model for measuring the insurance liabilities based on a three building blocks approach: expected future cash flows, discounted at risk-free rate, plus a margin for risk and uncertainties. However, there are key major differences between the two. Those differences concern several areas: future cash flows (only cash flows which are legally or contractually enforceable would be recognized), "market consistent" approach (in particular estimation of expenses should be based on a theoretical level of efficiency rather than on the own costs of the insurer), service margin (according to the IASB, to be transferred to another market participant), and upfront profit recognition of initial margins (rather than over time as for other long-term services). The European insurers disagree with the IASB view that such service margin concept is relevant. They also disagree that the retail market and the wholesale market for insurance would be the same. They think there is a significant difference between entry and exit prices, that is, a significant initial profit. The insurers are concerned by the consequences of those proposals, which would lead to a non-economic valuation of the insurance liabilities and a flawed pattern of profit recognition. Since the measurement of assets and liabilities in Solvency II project should be based on IFRS, the IASB accounting for insurance project could jeopardize Solvency II, which is currently based on an economic balance sheet approach. The CFO Forum has been supporting a market consistent measurement of liabilities for accounting purposes that is the same as proposed under Solvency II. The CFO Forum is considering alternatives for recognition of profit over the time of contracts when the risk is released and the services rendered to policyholders; these alternatives should be consistent with recognition of the initial profit margin as available capital for solvency requirements.

The Geneva Papers (2008) 33, 41-53. doi:10.1057/palgrave.gpp.2510163

Keywords: current exit value; market-consistent approach; guaranteed insurability; initial profit margin/service margin; profit recognition; Solvency II

\footnotetext{
* The CFO Forum is a high-level discussion group formed and attended by the Chief Financial Officers of major European (re)insurance companies: AEGON, Allianz, Aviva, AXA, BNPParibas assurances, CNP, Fortis, Generali, Hannover Re, If, ING, Legal \& General Group, Mapfre, Munich Re, Old Mutual, Prudential, Scottish Widows, Standard Life, Swiss Life, Swiss Re and Zurich Financial Services. Its aim is to discuss issues relating to financial reporting developments for their businesses and how they can create greater transparency for investors.
} 


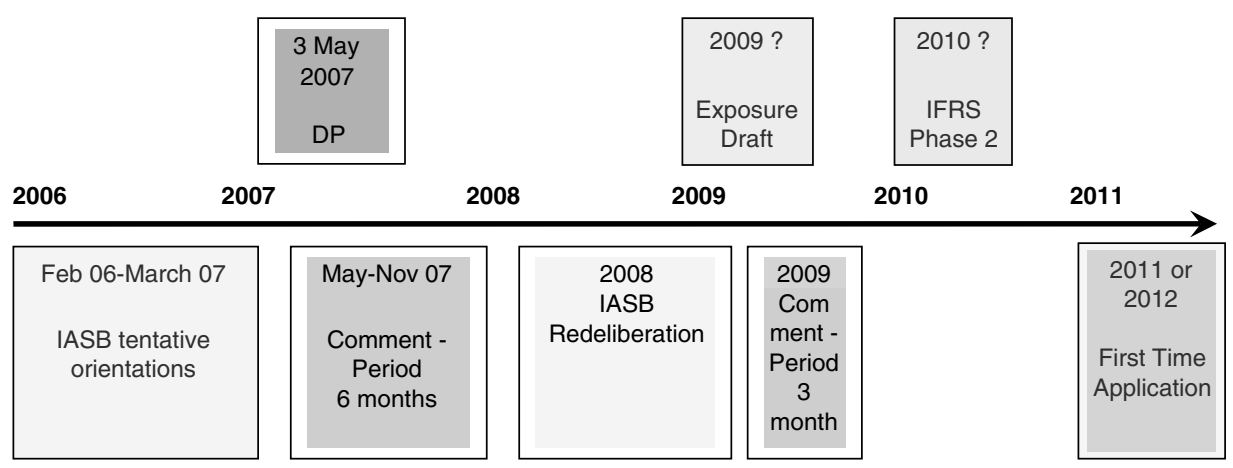

Figure 1. IASB Phase II Project Timetable.

\section{IASB Phase II project timetable}

On 3 May 2007, the IASB ${ }^{1}$ issued for comment a Discussion Paper on accounting for insurance and reinsurance contracts entitled Preliminary Views on Insurance Contracts ("the DP"). This is the second phase of the insurance contracts project, which in 2004 introduced an interim standard (IFRS 4 - Standard for Insurance Contracts) in order to allow the European listed insurance companies to comply with the European regulation and to establish their consolidated financial statements under IFRS for the periods starting in $2005 .^{2}$

The IASB project has been delayed. The DP was planned for the end of 2006 and the final standard by mid-2009. Actually, after a 6-month comment period ending on 16 November 2007, the next step will be redeliberation by the Board in 2008. Then an exposure draft of the phase II IFRS would not be expected before 2009 (within 18 months of the issuance of the DP) and the final standard within another 12 months (see Figure 1).

Further delays are possible because of work on convergence between IASB and FASB. ${ }^{3}$ The FASB has issued an Invitation to Comment containing the IASB Discussion Paper on 2 August 2007. The FASB will consider the responses (requested by 16 November) in deciding whether to add to its agenda a joint project with the IASB to develop a comprehensive standard on accounting for insurance contracts. If the FASB decides to be a party to this project, some additional delay would be likely.

\section{The IASB Phase II Discussion Paper}

\section{Overview of the Discussion Paper: key elements}

The DP proposes a single accounting model for life insurance and for property and casualty insurance based on a prospective measurement of insurance liabilities. In the

\footnotetext{
${ }^{1}$ International Accounting Standard Board, a private body that sets accounting standards for international financial reporting (IAS and IFRS).

${ }^{2}$ Cf. Duverne and Le Douit (2007).

${ }^{3}$ FASB $=$ U.S. Financial Accounting Standard Board.
} 
absence of an observable market for insurance liabilities, the insurance liabilities measurement would be based on three building blocks:

- projected future cash flows (current unbiased probability-weighted estimates);

- discounted at current market discount rate, excluding any factors that influence the observed rate but are not relevant to the liability (e.g., risks present in the instrument used as a benchmark but not present in the liability);

- including an explicit margin that market participants require for bearing risk (a "risk margin") and for providing other services, if any (a "service margin").

This approach defined as a "current exit value" corresponds to a "market consistent" transfer value (transfer at market conditions to another insurer of the assets and liabilities linked to the contracts):

- The assumptions should be updated at each closing.

- The estimates, including costs for handling the contracts and claims, should be based on market or portfolio data rather than on entity-specific data.

- The calculations should take into consideration each possible scenario: that would require stochastic calculations (to be performed at each closing).

- The "current exit value" would allow possible recognition of gain at inception. However, the day 1 profit would be limited to the actual amount of profit margin in the premium in excess of the risk and service margins (if any), which would be charged by reference market participants in a theoretical transfer (practically the Board does not expect in most cases significant profit at inception).

The Board has rejected the "current entry value", that is, to calibrate the margins to the premiums even if this approach could provide some observable reference.

The DP considers some specific topics: Future premiums, policyholder behaviour, guaranteed assurability and acquisition costs:

- Only premiums related to existing contracts should be recognized.

- The premiums that depend on policyholder behavior and are not under control of the insurer would not be recognized. However, recognition would include the future premiums that policyholders must pay to retain the right to guarantee continued coverage without confirmation of their own risk profiles, at a price that is contractually constrained.

- The insurer's right corresponding to this customer relationship is so close to the contracts that it should be recognized not as an asset but in deduction of the insurance liabilities.

- Acquisition costs should be expensed.

\section{Participating contracts}

- Expected policyholder participation rights should not be recognized as a liability (but as retained earnings) until the insurer has an unconditional or constructive 
enforceable obligation to transfer economic benefits to policyholders, current or future.

- Only if such an obligation comes into existence subsequently should the insurer recognize the resulting liability and an expense at that time.

\section{Unit of account, risk margin and diversification}

- The measurement of future probability-weighted cash flows would be performed on a contract-by-contract basis. Based on some statistical evidence, the result would be the same as at a portfolio level aggregation.

- However, the risk margins are affected by the size of the unit of account, that is, the portfolio of contracts subject to broadly similar risks and managed together.

- This approach allows for the effect of pooling of risks within portfolios but not for the effects of diversification or negative correlation of risks between portfolios (characteristics that are specific to an entity rather than a portfolio).

\section{Unbundling of insurance and financial (deposit) components}

The Phase II standard should apply to the whole contract if the components are so interdependent that they could only be measured separately on an arbitrary basis.

In the other cases:

- If the components are not interdependent, IAS 39 should apply to the deposit element and the Phase II standard should apply to the insurance element.

- If the components are interdependent but may be measured separately on a basis that is not arbitrary, IAS 39 would apply to the deposit element. The whole contract will continue to be accounted for under the principles of the Phase II standard with the insurance element measured as the difference between the amount for the whole contract and the deposit element.

The underlying rationale is the existence of the "deposit floor" under IAS 39 (the fair value of any financial instrument cannot be lower than the value on demand such as for banking deposits, whatever the behavior of the clients). The DP does not require such a deposit floor for insurance contracts but allows for taking into consideration expected probability-weighted cash flows. The IASB would prevent insurers making accounting arbitrage between IAS 39 and the Phase II standard.

\section{The CFO Forum's concerns with the DP}

\section{Similarities with CFO Forum elaborated principles}

The DP proposals might be deemed as broadly similar to the CFO Forum Elaborated Principles ("the EPs"):

- A single measurement model for life and non-life insurance.

- Same three building blocks approach: expected future cash flows, discounted at risk-free rate, plus a margin for risk and uncertainties.

- Market consistent approach.

- Current value (unlocking of assumptions at each closing). 


\section{But significant differences exist between IASB DP and the EPS}

Beyond the general concepts, there are major differences with the EPs.

IASB views are based on theoretical concepts that do not consider real life and its proposals contain significant flaws. This is illustrated in the following section, where some key topics are presented: future cash flows, market versus entity-specific assumptions, service margin and profit recognition. There are several other areas where the Board's proposals are different from the EPs, including for instance unbundling and own credit standing.

\section{Future cash flows}

The approach set out in the DP would limit the allowance for future premiums and, potentially, the ability to recognize all expected payments to policyholders under participating contracts; it would lead to significant cash flows being excluded from the contract value:

- While allowing for some customer relationship, the DP limits the recognition of future premiums and does not allow for a sound economical approach as in a transfer valuation; that would be the case for universal lifetime contracts or for deferred annuities contracts for instance.

- In the DP, participating rights should be recognized only if there is an enforceable obligation and not depend on the existence of an economic compulsion, which would be the criteria considered in a transfer.

This focus on legal obligations leads to valuations that do not give a reliable image of the economic reality. Unlike the DP, the EPs would allow for recognition of future cash flows on an economic basis to the extent that they are related to existing contracts.

\section{"Market-consistent" approach}

Both the DP and the EPs support the use of market-based assumptions.

The DP proposes that all estimates, including costs for handling the contracts and claims, should be based on market or portfolio data and not on entity-specific data.

- In areas where there is clear evidence of the existence of the market, the EPs and the DP proposals are the same: that includes financial data such as interest rates, inflation and macroeconomic data.

- The CFO Forum and the DP views are also similar for portfolio data such as mortality tables or claims occurrence.

- However, in other areas, the CFO Forum is of the view that assumptions should be based on what the entity expects to incur rather than the hypothetical market benchmark as proposed in the DP.

- It is in particular the case for expenses, where no reliable market data are available; an average market efficiency approach would be impractical, uneconomic and would trigger huge discussions with auditor. Even though the IASB indicates that in 
practice the insurers would generally refer to their own servicing costs, we are concerned that would place a burden of proof on insurers to demonstrate that their own costs are not significantly different from market participants costs.

- Moreover, this theoretical approach would result in information that is neither understandable nor relevant for users; assuming that expenses might be projected on a market average efficiency, we question the meaningfulness of financial information based on theoretical expenses and allowing artificial gains (if the insurer is less efficient than the market) or losses (if the insurer is more efficient than the market) to be recognized at inception and then offset over the term of contracts when recognizing the actual expenses.

\section{Service margin}

The DP envisages a service margin in addition to the risk margin.

- This concept would apply to other services provided by insurers as part of the contract such as investment management.

- According to the IASB, like the risk margin for insurance risk, the service margin would reflect the cost that the insurer would have to pay to transfer to another party the remaining portion of services.

- Said another way, the service margin would correspond to a compensation element that a third party would demand for delivering those services (like the risk margin for bearing insurance risks).

Clearly, that service margin is not consistent with existing transfer value approaches: for instance with the embedded value's well-established methodology that is used as reference in transfer valuation and also with the Solvency II project, where measurement of liabilities is based on a transfer approach and includes only the risk margin: "The value of technical provisions shall be equal to the sum of a best estimate and a risk margin... The risk margin shall be such as to ensure that the value of the technical provisions is equivalent to the amount insurance and reinsurance undertakings would be expected to require in order to take over and meet the insurance and reinsurance obligations". 4

Any margin in excess of the risk margin would not be transferred to another insurer, but would be kept by the transferor. Adding a service margin to the amount to be transferred would not represent economic valuation but would have the consequence of unduly increasing the amount of liabilities to policyholders to be recognized in the financial statements of insurers.

The elements of the proposed service margin in fact are captured (i) in the best estimate of future cash flows, which already incorporates the elements of servicing costs, and (ii) in the risk margin, which reflects the elements of compensation both for bearing risks and (implicitly) for providing services attached to the insurance contracts; the rest is part of the initial profit margin, that is, the difference between

\footnotetext{
${ }^{4}$ European Commission (2007, art 75, 1 and 3).
} 
the entry price (the premiums) net of acquisition costs and the exit price (marketconsistent transfer value) composed of the discounted amount of the best estimate of future cash flows plus the risk margin.

Actually, the question is whether this initial profit margin is significant and how the profit should be recognized. That key question is addressed in the following section.

\section{Profit recognition}

The profit recognition model has been addressed in the DP only indirectly (in a few paragraphs and there is no specific question for comment), although it is a crucial issue (we point out that the IASB has been much divided on this subject: seven members supported upfront profit recognition against six and one abstention).

As a consequence of the current exit value model, the DP allows for day 1 recognition of any initial profit margin.

However, according to the IASB, there should not be any significant difference between entry and exit prices for insurance contracts, and consequently no significant profits exist to be recognized at inception.

- The DP is based on the IASB's view that there is one single market for insurance contracts as for any financial instruments, for instance for listed equity stocks. The Board does not make distinction between the retail ${ }^{5}$ market (between policyholders and insurers) and the wholesale ${ }^{6}$ market (between insurers, where occasional transfers would occur): in its view, the entry price on the retail market should equal the exit price on the wholesale market.

- If there are retail profits exceeding significantly wholesale profits, that should not last due to the law of bid and ask and the competition between insurers for market shares.

- In the Board's view, except under exceptional circumstances (e.g. niche market), the difference between entry and exit prices should only result from transaction costs (as it is in stocks exchange markets); if there are other differences between entry and exit prices, that would not relate to the insurance obligation but to "fees" for separate services performed at inception.

- The DP is very vague on what could be those separate services rendered to the policyholders at inception. It proposes a rationale based on the compensation the insurer is entitled to for assembling portfolios (what is the core business of insurance, but to mutualize risks and that too in a permanent way over the time of contracts and not only at inception).

- Because the insurers would have rendered such added value at inception, upfront recognition in the income statement of the corresponding "fees" included in the "entry price" would be justified.

\footnotetext{
${ }^{5}$ IASB (2007, § 99 "entry, primary or retail").

6 IASB (2007, § 99 “"exit, secondary or wholesale”).
} 
The industry does not support these views and notes that there is a significant difference between the entry price observed in transactions with policyholders and the exit price in a transaction between insurers. It is because there are two different markets: the retail market and the wholesale market. As for any other goods and services, the prices are different depending on the market where the transaction takes place. For instance for potatoes, prices at the shop around the corner are higher than they are at a regional wholesale distribution centre where all shops get their supply.

To illustrate the materiality of the initial profit margin in insurance, we can use as a proxy the calculations made for European Embedded Value (EEV). In 2006, 11 members of the CFO Forum produced EEV figures on a market-consistent basis: ${ }^{7}$

- For newly written business in 2006, the aggregate initial profit margin (New Business Value) for these 11 insurers was over euro 5.2 billion.

- This represents about 4.5 per cent of the premiums received for the newly written business in the year, or about 2.4 per cent of the present value of all premiums expected to be received over the life of the business (additional margins are of course present for prior generations of business as well).

The European insurers agree on measurement: they are supporting an exit value model based on a transfer approach for valuing insurance liabilities in the balance sheet (consistently with valuation of assets at fair value).

However, this does not mean that the initial profit margin in excess of the transfer value should be recognized at inception as a gain in the income statement. The profit has not been earned through the act of selling the insurance contracts but only when the performance of the services to the policyholders has been completed. It is the reason why the EPs propose that profit should be recognized when the risk is released and the linked services are provided over the time of contracts. This is consistent with the recognition of profit for services under IASB standards.

This is not a measurement question but a presentational one.

The CFO Forum has considered three alternatives for classification and recognition of the initial profit margin:

- As a separate liability component in addition to the liability to policyholders, and separately disclosed.

- As a separate equity component.

- As a profit directly recognized in P\&L at inception.

○ The last solution, day 1 profit recognition, is not consistent with the view that profit must be recognized over the time of contracts and contradicts the EPs. Moreover while this solution is possible under Solvency II, insurance regulators and supervisors would be very reluctant to admit it and could question the level of the initial profit margin; they might be tempted to increase the risk margins so that does not lead to major profit at inception.

\footnotetext{
${ }^{7}$ This basis provides for financial market risk in the same way as the BEL proposed by the IASB, and in addition reflects deductions for cost of capital held and non-financial risk that are a reasonable proxy for the risk margin.
} 
$\bigcirc$ The first and the second options differ only on initial presentation of the profit margin in equity or in liability; in both solutions, the profit margin would be released through an income statement when the risk is released and the services rendered to policyholders. These two solutions are consistent with the view that profit must be recognized over the time of contracts and so with the treatment of other long-term service contracts under current IFRS.

O The second option, equity classification, would be both consistent with the EPs and coherent with Solvency II. But it may not be favored by the IASB, as they have indicated an intention to gradually eliminate balance sheet movements that do not go through the income statement.

o The first proposal, liability classification, is consistent with the EPs (nil profit at inception) and with IASB standards. For solvency purposes, this solution should not be an issue because the core liability, that is, the liability to policyholders, would not be impacted by the profit margin and there would be a full transparent disclosure of the profit margin.

O The CFO Forum has expressed a preference for the "liability classification", to the extent that this would not prejudice the Solvency II position.

\section{Implications for solvency}

Both the European Commission and the IAIS $^{8}$ consider that it is most desirable to have insurance liabilities measurement for solvency purposes equal to or substantially consistent with measurement under IFRS (for instance, supervisors would require an adjustment for removing the own credit standing impact, if IFRS requires to take it into account; on the other hand, supervisors would require to include in the liabilities future participating rights if the IFRS would not allow it for recognition as a liability).

The industry does share the supervisors' position in favor of consistent basis for obvious reasons.

Because the Phase II project is still at the stage of the DP, the European Commission has had to anticipate the measurement of insurance liabilities in the first pillar of European Solvency II: the project is based on an economic balance sheet approach. The insurers support insurance liabilities valuation on a "marketconsistent" transfer value basis as proposed in the Solvency II Framework directive quoted above. ${ }^{9}$ For unhedgeable risks, the amount of liabilities should be equal to the best estimate of future cash flows discounted at a risk-free rate plus a risk margin calibrated to the cost of capital methodology.

The proposals of the IAIS for insurance liability measurement are quite similar. Based on the principle that "similar obligations with similar risk profiles should result in similar liabilities", the IAIS supports the use of market-consistent measures to the extent possible and believes that the three building blocks approach provides an appropriate methodology in the absence of observable market for insurance liabilities. ${ }^{10}$

\footnotetext{
${ }^{8}$ IAIS: International Association of Insurance Supervisors.

${ }^{9}$ See the sub-section on Service margin.

${ }^{10}$ See First Liabilities Paper (IAIS (2005)) and Second Liabilities Paper (IAIS (2006)), www.iaisweb.org.
} 
If the profit margin is included in the accounting liability, the accounting liability would be higher than the economic amount to be recognized for Solvency II purposes.

We have expressed above the view that such accounting classification of the profit margin should not jeopardize the Solvency II position. In particular, this should not deter the insurance supervisors from continuing to recognize the profit margin component as available capital (Tier 1) and not as hybrid capital (Tier 2) for solvency purposes, even if this component were classified as liability rather than as equity.

\section{What shall we look for? Next steps}

In addition to the key issues described above (future cash flows, exit value, margins, profit recognition), there are some other key topics on which the industry must further elaborate:

- Investment contracts with and without discretionary participating features ("DPF"):

o Should they be in the scope of IFRS Insurance Phase II or in IAS 39?

O A possible solution would be to have:

- investment contracts with DPF in the scope of Insurance IFRS; and

- contracts without DPF under IAS 39 with alignment of FV on the insurance "current exit value" definition (especially removing the deposit floor);

- while keeping option for amortized cost in IAS 39.

- Need for particular attention to banking activities of bancassurance groups.

- Unit of account and diversification effect between lines of business

- The risk margin should be determined at the level of the portfolio. The insurers consider that the portfolio basis should be consistent with how the business is managed. The EPs propose to define the portfolio as a "group of contracts managed together when assessing the risks". That would reflect the business model employed by insurers and would allow for taking into account the effect of negative correlations, for example between term insurance and annuity contracts. According to the IASB, liabilities should be measured independently of the insurer that holds the portfolio, hence without taking into account diversification across different portfolios.

Insurers would support diversification between portfolios to be recognized. An open question is: should the diversification effect be entity specific (consistent with EEV) or based on a "standardized", that is, "market" basis (transfer to a "well-diversified market participant", as it could be considered in a transfer at market conditions, independently from the level of diversification of the transferor or the transferee)?

\section{Review of the EPs}

Conversely, the DP creates an opportunity to reconsider some proposals under EPs, for instance:

- the role of "shock absorber" of the profit margin (for non-financial assumptions changes), 
- customer intangible assets (acquisition costs/geographical issues), and

- renewals in P\&C business (for solvency: future profitable contracts should be recognized even if there is no constraint).

\section{Presentational issues-Income statement}

The IASB has not yet made proposals for the presentation of the income statement. It has only raised limited questions of whether the premiums should be presented as revenues through the P\&L or directly as deposits in the balance sheet, what items should be presented on the face of the income statement and whether the income statement should include all changes in the insurance liabilities.

The insurers have to consider the opportunity to make proposals when commenting on the DP. In any case, proposals should respond to the needs of the users (financial analysts and investors), especially for free cash-flow information, and for conveying information on the profit drivers and providing attribution analysis. The proposals should take into consideration the switch from locked-in assumptions to unlocked assumptions and the resulting volatility.

A single presentation model of the income statement for life and non-life insurance would be consistent with, and reflect, the single measurement model supported by European insurers and by the IASB.

This single model could be presented on a margin model approach, which is better adapted to the current prospective measurement model and would allow for explanation of the profit drivers rather than a traditional approach. The traditional information on premiums would not reflect the prospective net premium value (NPV), which is projected in the discounted future cash flows (first and second building blocks). Instead, the NPV is contained in the EEV reporting. Also, the traditional presentation would not picture the cash basis information, which is described in the cash flow statement.

But many insurers object that the presentation of the income statement for $\mathrm{P} \& \mathrm{C}$ is not broken and therefore should not be changed.

With a margin model presentation of the income statement, premiums and claims would no longer be presented on the face of the income statement but in the cash flow statement, in the segmental income statement and in separate supplemental disclosures such as liability roll-forward, which would include information needed for P\&C ratios such as claim and combined ratios.

Volatility in the financial statements is a critical issue. Any accounting mismatch must be remote. In particular, one means to avoid fictitious volatility is to have symmetrical recognition of changes in the value (fair value) of assets and changes in the "current exit value" of liabilities; that means to the extent that IAS 39 allows for changes in the value of the available for sale assets category to be recognized through equity changes in the value of insurance liabilities due to financial assumptions should be recognized through equity and not directly in P\&L.

\section{Next steps}

After having commented on the DP, the priority for the industry during the next months will be to continue discussions with the IASB directly or through the 
IASB Insurance Working Group, which is expected to reconvene by March or April 2008. In addition to the technical issues addressed above, the industry and the IASB will have to establish a process to test and later to implement the proposals, given the fundamental changes proposed with the introduction for accounting purposes of a prospective current assumption measurement model. Testing should include quantitative work such as QIS $^{11}$ for Solvency II.

The industry will have to further communicate towards the other stakeholders:

- the European Commission, the CEIOPS and the IAIS;

- the analysts, investors and rating agencies;

- the audit firms;

- the EFRAG and the European national standard-setters;

- the FASB to the extent that it would decide to put the IASB project on its agenda.

In the meantime, the industry has to complete the comparison between proposals for Accounting/EEV/Solvency, which have:

- similarities of approaches at high level;

- but differences in the level of guidance: high-level principles for accounting/EEV detailed guidance/Solvency II detailed specifications with implementation measures of the Solvency II Framework directive (cf QIS 3 specifications as a model of what might be the implementation measures to be decided by the Commission).

The industry has to achieve an appropriate resolution on the emergence of profit margins in earnings and the related disclosures of risks and profit margins for financial information users and for supervisors.

The insurers support a principle-based accounting standard. This means that no prescriptive requirements should be set up by the IASB or other bodies. Conversely, the insurers would be advised to start a reflection on how the guidance could be elaborated in order to allow for comparability and consistency across the global insurance industry.

Those tasks should be performed while closely monitoring (and commenting) on both the other IASB projects and the Solvency II and IAIS projects.

Eventually, the industry would also need to reflect on possible tax implications of the IFRS Phase II model at the national level.

\section{Conclusion}

The European industry welcomed the IASB DP as an important step for replacing the temporary flawed accounting standard IFRS 4 . The IASB DP on insurance could have represented a good starting point towards an accounting reflecting the insurance business model.

However, the DP is built around theoretical accounting concepts and an underlying rationale that do not accurately capture the economic realities of insurance.

\footnotetext{
${ }^{11}$ QIS: quantitative impact studies.
} 
European insurers believe that the IASB's proposals would lead to a non-economic valuation of the insurance liabilities in contradiction with its objectives and with required "market-consistent" approaches (market consistent embedded value and solvency projects (IAIS and Solvency II).

Furthermore, the insurers are concerned with the industry being used as a "guinea pig" by the IASB. This is reflected in the complexity and highly theoretical nature of some of the proposals, which are also considered under other projects (liabilities/ equity, revenue recognition, fair value measurement, etc.).

Should the DP proposals be converted into the future Phase II standard without substantial modifications, the insurance industry would remain handicapped compared with the other industries.

The insurance industry remains eager to contribute with the IASB to the development of a comprehensive and accurate financial reporting for insurance consistent with the current solvency purpose. In this context, the willingness of the industry to speak with one voice is key.

\section{References}

Duverne, D. and Le Douit, J. (2007) 'IFRS for insurance: CFO Forum proposals', The Geneva Papers on Risk and Insurance - Issues and Practice 32: 62-74.

European Commission (2007) Proposal for a Directive of the European Parliament and of the Council on the taking-up and pursuit of the business of insurance and reinsurance - Solvency II, European Commission SEC (2007) 870 \& SEC (2007) 871, Brussels, 10 July.

IAIS (2005) Issues Arising As a Result of the IASB's Insurance Contracts Project - Phase II Initial IAIS Observations - Phase II Initial IAIS Observations, Basel: IAIS (May).

IAIS (2006) Issues Arising As a Result of the IASB's Insurance Contracts Project - Phase II Second Set of IAIS Observations, Basel: IAIS (May).

IASB (2007) Preliminary views on insurance contracts Discussion paper, IASB, London, available at http://www.iasb.org/Current + Projects/IASB + Projects/Insurance + Contracts/Insurance + Contracts.htm.

\section{About the Authors}

Denis Duverne is Chief Financial Officer of AXA Group - Finance, Control and Strategy and chairman of the CFO Forum. He graduated from HEC Business School and from the Ecole Nationale d'Administration. Denis Duverne joined AXA in 1995 and its Executive Committee in January 2000, as Executive Vice President, Finance, Control and Strategy. Since February 2003, he is a member of the Management Board of AXA, in charge of Finance, Control and Strategy.

Jacques Le Douit is Chairman of the Accounting committee of the French Insurance Association (FFSA), Chairman of the Accounts Committee of the "Comite Européen des Assurances" (CEA) and a member of EFRAG Insurance Accounting Working Group (previously Insurance Sub Committee). 